\title{
EFEITO DA DISPONIBILIDADE DE ÁGUA E DE LUZ NA COLONIZAÇÃO MICORRÍZICA E NO CRESCIMENTO DE Tabebuia avellanedae Lorentz ex Griseb. (BIGNONIACEAE) ${ }^{1}$
}

\author{
Eliane Maria Moratelli², Murilo Dalla Costa ${ }^{3}$, Paulo Emílio Lovato ${ }^{4}$, Marisa Santos ${ }^{5}$ e Maria Terezinha \\ Silveira Paulilo 5
}

\begin{abstract}
RESUMO - Em plantas cultivadas em substrato não esterilizado, inoculado ou não com fungos micorrízicos arbusculares, analisou-se, através de dois experimentos em separado, o efeito de quatro intensidades de luz $(70 \%, 50 \%, 30 \%$ e $4 \%$ da luz solar incidente) e de dois regimes hídricos (saturado e insaturado) sobre o crescimento e micorrização de plântulas de Tabebuia avellanedae Lorentz ex Griseb. (ipê-roxo; Bignoniaceae). As variáveis analisadas foram área foliar, massa seca à altura do caule, taxas de crescimento, densidade estomática, teor de prolina e intensidade de colonização micorrízica. As plântulas apresentaram diferenças morfológicas, fisiológicas e na intensidade de colonização micorrízica, em função dos tratamentos aplicados. Essas diferenças foram no sentido de minimizar os possíveis estresses causados por intensidade luminosa e disponibilidade hídrica desfavoráveis. Os resultados permitiram o relato de que os ajustamentos morfológicos e fisiológicos apresentados pela espécie podem conferir a ela vantagens no estabelecimento de plântulas em clareiras e ambientes mais secos e, também, na sobrevivência em ambientes mais sombreados.
\end{abstract}

Palavras-chave: Ipê-roxo, desenvolvimento inicial e micorriza arbuscular.

\section{EFFECT OF WATER AND LIGHT AVAILABILITY ON MYCORRHIZAL COLONIZATION AND GROWTH OF Tabebuia avellanedae Lorentz Griseb. (BIGNONIACEAE)}

\begin{abstract}
Two separate experiments analyzed the effect of four light intensities $(70 \%, 50 \%, 30 \%$ and $4 \%$ of incident solar light) and two water regimes (saturated and non-saturated) on the growth and intensity of mycorrhizal colonization of Tabebuia avellanedae ex Lorentz Griseb. (purple trumpet tree; Bignoniaceae), in plants cultivated in non-sterilized substratum, inoculated or not with arbuscular mycorrhizal fungi. The analyzed parameters were leaf area, dry mass, stem height, growth rates, stomatal density and proline concentration. The plants presented differences in morphology, physiology and in the intensity of mycorrhizal colonization according to the applied treatments. The differences showed by the plants were in the sense of minimizing the possible stresses caused by unfavorable light intensity and water regime The results obtained allow to suggest that the morphological and physiological adjustments presented by the species can bring advantages for the establishment of plants in gaps and dry environments and also for the survival in more shaded environments.
\end{abstract}

Keywords: Purple trumpet tree, early development and arbuscular mycorrhizal.

\footnotetext{
${ }^{1}$ Recebido em 19.10.2006 e aceito para publicação em 29.03.2007

${ }^{2}$ Mestre em Biologia Vegetal. Departamento de Botânica. Universidade Federal de Santa Catarina(UFSC).E-mail:<elianem2@pop.com.br>

${ }^{3}$ Programa de Pós-Graduação em Recursos Genéticos Vegetais da UFSC. E-mail:<mdallac@ bol.com.br>.

${ }^{4}$ Departamento de Engenharia Rural da UFSC.Av.Admar Gonzaga, 1346, 88034-001 Florianópolis-SC. E-mail: <plovato @ mbox1 ufsc.br.>

${ }^{5}$ Departamento de Botânica da UFSC, 88040-900 Florianópolis, SC. E-mail: <marint@ mbox1.ufsc.br>; <paulilo@ccb.ufsc.br>.
} 


\section{INTRODUÇÃO}

A espécie Tabebuia avellanedae Lorentz ex Griseb (ipê-roxo), Bignoniaceae, ocorre na Floresta Tropical Atlântica, sendo considerada espécie secundária tardia na sucessão florestal (SOARES et al., 2003; ZANGARO et al., 2003). O estudo da regeneração do ipê-roxo é de grande importância, uma vez que, devido às suas propriedades medicinais e lenho de grande valor comercial, já esteve sob o risco de extinção. A regeneração natural das espécies das florestas tropicais é afetada pelas condições ambientais presentes durante o estabelecimento das plântulas e pela capacidade destas em resistir a esses estresses. Nesses ambientes, disponibilidade de luz, de água e de nutrientes varia no tempo e espaço e é considerado o fator abiótico que mais afeta o estabelecimento das plântulas (EVANS e EDWARDS, 2001). A capacidade da espécie em adequarse morfológica e fisiologicamente às variações na disponibilidade de recursos e em associar-se com fungos micorrízicos arbusculares (FMA) favorece o estabelecimento de plantas em ambientes limitantes em água e luz (EVANS e EDWARDS, 2001; HURST et al., 2002). No entanto, também a associação micorrízica entre raízes e FMA é influenciada, entre outros fatores, pela intensidade de luz (GEHRING, 2003) e pela disponibilidade de água (ENTRY et al., 2002).

Os objetivos deste trabalho foram: a) verificar em T. avellanedae a hipótese de que plântulas da espécie são capazes de minimizar os efeitos de estresse de água e luz, adequando-se sua morfologia e fisiologia às diferentes disponibilidades de água e luminosidade e associando-se a fungos micorrízicos; e b) especular, com base nos resultados, sobre a capacidade de estabelecimento da plântula nos diferentes ambientes da floresta tropical.

\section{MATERIAL E MÉTODOS}

Foram utilizadas plântulas de Tabebuia avellanedae Lorentz ex Griseb. (Bignoniaceae) com um mês de idade, obtidas da germinação de sementes, padronizadas por tamanho (cerca de $5 \mathrm{~cm}$ de altura e apresentando um par de folhas). As plântulas foram plantadas em sacos plásticos pretos de $2 \mathrm{~L}$ (uma planta por saco), contendo substrato composto de Nitossolo Vermelho Distroférrico, composto termofílico e areia (1:1:1), não esterilizado, inoculado ou não com $1 \mathrm{~g}$ de inóculo micorrízico de Glomus clarum Nicol. Schench (isolado no 31 ) e $G$. etunicatum Becker e Gerdemann (isolado no 69).
Para o experimento de intensidade luminosa, foram utilizadas 80 plântulas, sendo 20 plantas por tratamento de luz, 10 em substrato inoculado e 10 em substrato não-inoculado. As plantas foram colocadas sob armações de madeira de $1,0 \mathrm{~m}^{3}$ recobertas com tela de polietileno de cor preta de diferentes malhas, permitindo a passagem de $70 \%, 50 \%, 30 \%$ e $4 \%$ da luz solar incidente. Aradiação fotossinteticamente ativa (RFA) em cada tratamento foi determinada através de um quantômetro, LICOR 250 , com sensor para a faixa de radiação entre 400 e $700 \mathrm{~nm}$, medida ao meio-dia, de um dia claro, sendo, respectivamente, de $600 \mu \mathrm{mol} \mathrm{m}^{-2} \mathrm{~s}^{-1}, 430 \mu \mathrm{mol} \mathrm{m}{ }^{-2} \mathrm{~s}^{-1}, 258$ $\mu \mathrm{mol} \mathrm{m} \mathrm{m}^{-2} \mathrm{~s}^{-1}$ e $34 \mu \mathrm{mol} \mathrm{m} \mathrm{m}^{-2} \mathrm{~s}^{-1}$. Cada tratamento de luz conteve 20 plantas, 10 em substrato inoculado e 10 em substrato não-inoculado. As plantas foram irrigadas com água de torneira a cada dois dias.

Para o experimento de estresse hídrico, foram utilizadas 60 plântulas, 30 em regime hídrico saturado e 30 em regime hídrico não-saturado, sendo que em cada regime hídrico havia 15 plântulas em substrato inoculado e 15 plântulas em substrato não-inoculado (12 plantas para medidas de crescimento e densidade estomática e três plantas para medição de prolina). As plântulas foram colocadas sob armações de madeira, recobertas com tela de polietileno preta. Para impedir a irrigação das plantas por água da chuva, as caixas foram colocadas sob cobertura de plástico transparente. Nesse sistema, as plantas receberam $44 \%$ da luz solar incidente (RFA máxima de $490 \mu \mathrm{mol} \mathrm{m}^{-2} \mathrm{~s}^{-1}$ ). A rega das plantas foi feita com água de torneira, até a percolação, a cada dois (regime hídrico saturado) ou 20 dias (regime hídrico não- saturado). Para o tratamento de estresse hídrico, o intervalo entre regas consecutivas foi determinado em experimento prévio, escolhendo-se o intervalo em que foi possível identificar visualmente menor crescimento das plantas. Após 20 dias sem irrigação, a porcentagem de água do solo em deficiência hídrica (Ucc\%) em relação ao solo em capacidade de campo (Ucc) foi de $24 \%$, calculada pela equação Ucc\% = Udf x 100/Ucc, em que Udf é a umidade do solo em deficiência hídrica. A Udf foi determinada pela equação Udf = Mdf - Msdf/ Msdf, em que Mdf é a massa do solo em deficiência hídrica (após 20 dias sem irrigação), e Msdf é a massa seca do solo em deficiência hídrica, secado em estufa até a retirada completa de água.

Os experimentos foram montados em blocos completamente casualizados. As plantas permaneceram nessas condições durante três meses, quando foram 
coletadas para as análises. Uma primeira coleta foi feita antes de as plantas serem submetidas aos tratamentos.

Os experimentos foram conduzidos de abril a julho de 2005, em área a céu aberto do Departamento de Botânica da Universidade Federal de Santa Catarina, Município de Florianópolis, $27^{\circ} 35^{\prime} \mathrm{S}$ e $48^{\circ} 34^{\prime} \mathrm{W}$, altitude de 2 $\mathrm{m}$, sendo no período a temperatura média máxima e mínima de $31^{\circ} \mathrm{C}$ e de $11^{\circ} \mathrm{C}$, respectivamente, e a precipitação média de $121 \mathrm{~mm}$.

A área foliar foi obtida delineando-se os contornos das folhas em papel, sendo a área dentro dos contornos determinada através de planímetro digital (Haff-Digiplan). A massa seca, de raiz, caule e folhas foi obtida por pesagem após a secagem do material vegetal em estufa a $80^{\circ} \mathrm{C}$, por $48 \mathrm{~h}$. A altura do caule foi mensurada com uma régua milimetrada, medindo-se desde a região do colo até o ápice caulinar.

A taxa média de crescimento relativo (TCR) e a razão média de área foliar (RAF) foram calculadas segundo Hunt (1982), utilizando-se as equações TCR $=\left(\mathrm{Ln} \mathrm{m}_{2}\right.$ - $\left.\mathrm{Ln} \mathrm{m} \mathrm{m}_{1}\right) / \mathrm{t}_{2}-\mathrm{t}_{1}$ e $\mathrm{RAF}=\left[\left(\mathrm{A}_{1} / \mathrm{m}_{1}\right)+\left(\mathrm{A}_{2} / \mathrm{m}_{2}\right)\right] / 2$, em que: $\mathrm{Ln}=$ logaritmo neperiano; $\mathrm{m}=$ massa seca da planta; $\mathrm{t}_{2}-\mathrm{t}_{1}=$ intervalo de tempo entre as coletas 1 e 2 ; e $\mathrm{A}=$ área foliar.

O teor de prolina foi determinado pelo método de Bokhari e Trent (1985). Foram utilizadas três plantas por tratamento, sendo de cada planta retiradas as duas últimas folhas completamente expandidas, resultando em seis folhas por tratamento. As seis folhas por tratamento foram picadas e misturadas, e três porções de $500 \mathrm{mg}$ de material picado foram macerados separadamente em $10 \mathrm{~mL}$ de solução aquosa de ácido sulfossalicílico (3\%). Os extratos foram centrifugados, e dos sobrenadantes foram retiradas três alíquotas de $2 \mathrm{~mL}$. A cada alíquota foram acrescentados $2 \mathrm{~mL}$ de ácido acético glacial e $2 \mathrm{~mL}$ de nihidrina ácida $(1,25$ g de nihidrina, $30 \mathrm{~mL}$ de ácido acético glacial e $20 \mathrm{~mL}$ de ácido fosfórico $6 \mathrm{M}$, em banho-maria a $70^{\circ} \mathrm{C}$, com agitação). Os tubos contendo as soluções foram colocados em banho-maria a $100^{\circ} \mathrm{C}$ e após $1 \mathrm{~h}$. Foram colocados em gelo para o término da reação. Foram acrescentados $4 \mathrm{~mL}$ de tolueno a cada tubo e homogeneizados através de agitação. Após a separação de fases, da fração com tolueno foi retirada uma alíquota de $1 \mathrm{~mL}$, sendo sua absorbância lida a $520 \mathrm{~nm}$. O teor de prolina da fração de tolueno foi calculado através da comparação da absorbância de soluções-padrão de prolina.

\subsection{Determinação da densidade estomática}

A densidade estomática foi medida em impressões da epiderme das folhas, aplicando-se esmalte incolor para unhas sobre a epiderme, retirando a película de esmalte depois de seco. Para cada um dos quatro tratamentos, dois regimes hídricos (saturado e nãosaturado) e dois substratos (inoculado e não-inoculado) foram utilizados três plantas; de cada planta foram utilizadas duas folhas completamente expandidas, e de cada folha foram utilizadas duas réplicas do terço médio do folíolo apical, nas regiões intercostais da face abaxial da superfície foliar. De cada réplica foi quantificado o número de estômatos em cinco campos. A quantificação foi feita com o auxílio de microscópio óptico, aferindo o diâmetro do campo microscópico, em 400x, para determinação da área em $\mu \mathrm{m}^{2}$. Os dados apresentados foram transformados em número de estômatos por $\mathrm{mm}^{2}$.

A quantificação da freqüência e intensidade de colonização micorrízica foi feita por meio da observação ao microscópio óptico de fragmentos de raízes (TROUVELOT et al., 1986) após a clarificação e coloração, segundo Gianinazzi e Gianinazzi-Pearson (1992).

Os resultados obtidos atenderam aos pressupostos de normalidade e homogeneidade de variâncias, sendo comparados por análise de variância, com teste F, e complementados pelo teste de Tukey a 5\% (BANZATO e KRONKA, 1995). Todas as análises foram realizadas utilizando-se o programa de software Statistica, versão 6.0 (STATSOFT, 2001). Os experimentos de luminosidade e regime hídrico não foram comparados entre si.

\section{RESULTADOS E DISCUSSÃO}

\subsection{Influência da luz e da colonização por FMA no crescimento de plantas}

A resposta das plantas de Tabebuia avellanedae à variação de luz em plantas colonizadas por FMA selecionados foi similar à de plantas colonizadas por FMA nativos (Figuras 1, 2, 3 e 4). Entretanto, Soares et al. (2003) encontraram menor crescimento de plantas de T. heptaphyla Vell. Tol. colonizadas por FMA nativos em relação àquelas colonizadas por FMA selecionados. Essa discrepância entre os resultados aqui encontrados e os de Soares et al. (2003) é esperada, já que a interação entre FMA e uma espécie vegetal é influenciada tanto pela espécie do fungo quanto pela espécie hospedeira e pelas condições edafoclimáticas (SMITH e GIANINAZZI-PEARSON, 1988).

R. Árvore, Viçosa-MG, v.31, n.3, p.555-566, 2007 
a

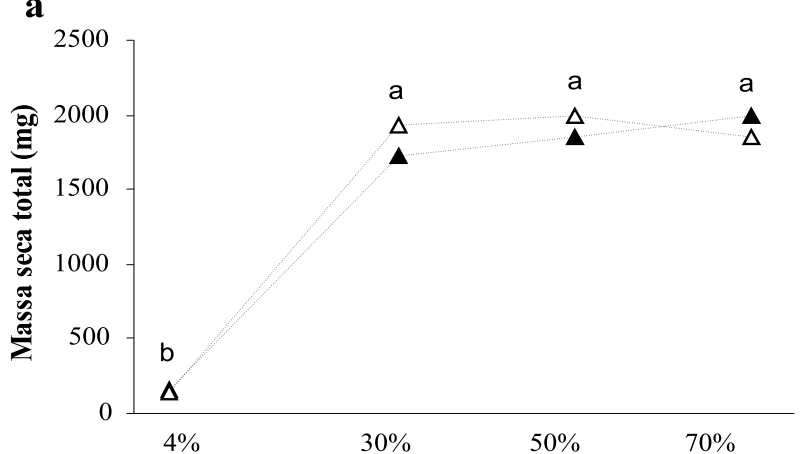

c

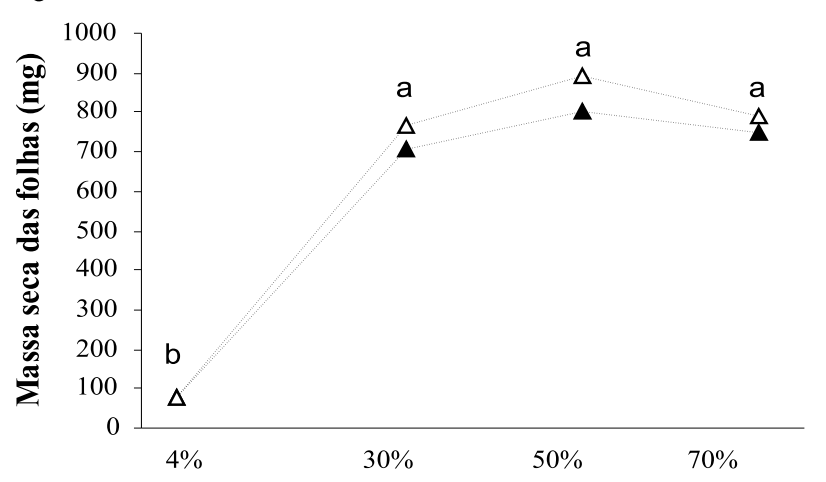

b

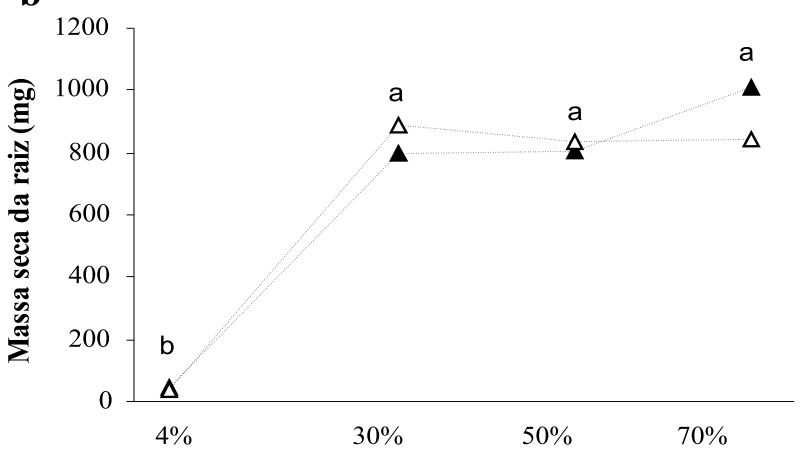

d 1200

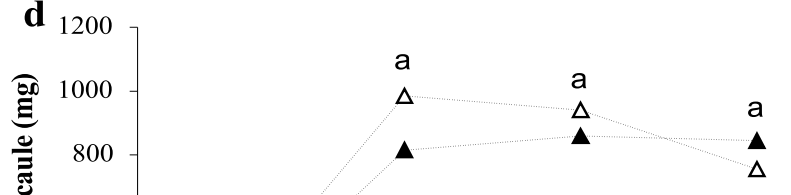

Intensidade de luz solar

Figura 1 - a) Massa seca total, b) massa seca da raiz, c) massa seca das folhas e d) massa seca do caule de plantas de Tabebuia avellanedae Lorentz ex Griseb. cultivadas por três meses em diferentes intensidades de luz e colonizadas por fungos micorrízicos selecionados $(\boldsymbol{\Delta})$ ou nativos $(\triangle)$.Valores com a mesma letra, para o efeito luz, não diferem significativamente entre si, pelo teste de Tukey $(\mathrm{p} \leq 0,05)$.

Figure 1 -a) Total dry mass; b) root dry mass; c) leaf dry mass; d) stem dry mass of Tabebuia avellanedae Lorentz Griseb. cultivated during three months under different light intensities and colonized by selected $(\mathbf{\Delta})$ or native $(\triangle)$ mycorrhizal fungi. Letters compare light treatments. Means followed by the same letter are not significantly different by the Tukey test $(p \leq 0.05)$.

O crescimento das plantas foi afetado pela intensidade luminosa (Figura 1ad). Em baixa intensidade (4\% da luz solar), a biomassa foi significativamente menor que em intensidades mais altas $(30 \%, 50 \% \mathrm{e}$ $70 \%$ da luz solar). Entretanto, a espécie apresentou certa plasticidade para ajustamentos que levam a minimizar o estresse causado pelo excesso ou limitação de luz. Quando houve limitação de luz (4\% de luz), a razão raiz/parte aérea foi menor que em intensidade de luz; mais, o que favorece a captação de luz, nas intensidades mais altas de luz, a razão raiz/parte aérea foi maior, o que favorece a captação de água (LEE et al., 1999). A intensidade de luz influenciou significativamente $(\mathrm{p} \leq 0,01)$ a taxa de crescimento relativo (TCR) e a razão de área foliar (RAF). A TCR das plantas a $4 \%$ de luz foi a mais baixa que nas outras intensidades de luz, havendo um aumento da TCR com incremento de luz de $30 \%$ para $70 \%$ de luz (Figura 3a). A RAF foi maior a $4 \%$ de luz que em intensidades mais altas de luz (Figura 3b). A razão de área foliar (RAF) foi maior na mais baixa intensidade de luz e menor nas intensidades mais altas. Esse comportamento da RAF tem sido associado, no primeiro caso, a favorecer a captação de luz e, no segundo caso, a inibir a transpiração (POORTER, 1999). A taxa de crescimento relativo (TCR) é produto da razão raiz/ área foliar RAF pela taxa de assimilação líquida (TAL), conforme Hunt (1982). Em baixa intensidade de luz houve aumento da RAF, o que contribui para uma maior TCR, ajustamento esse que pode conferir às plantas de $T$. avellanedae maior potencialidade para sobreviver à baixa intensidade de luz da mata fechada, levando a uma TCR positiva nessas plantas. 

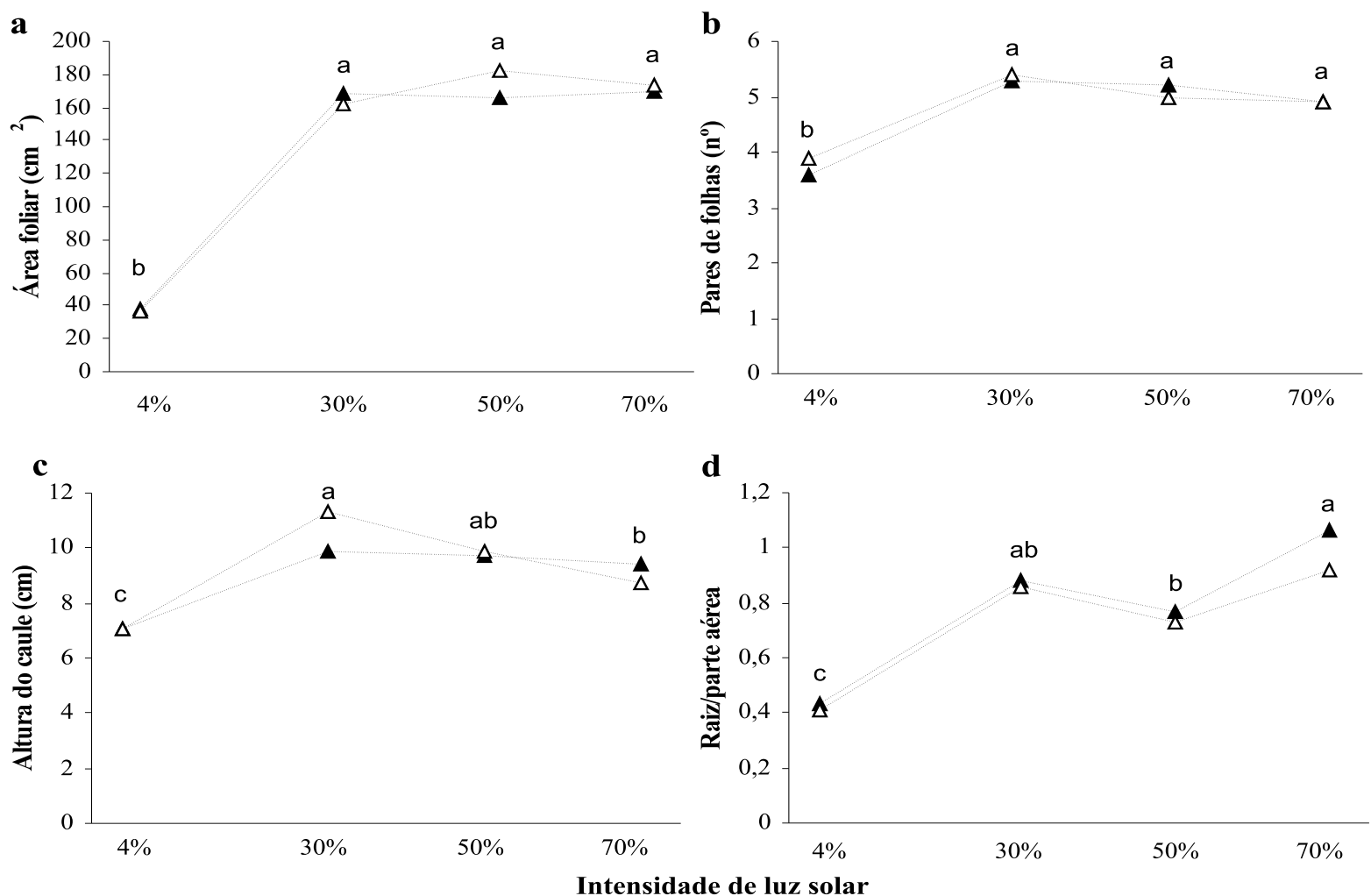

Figura 2 - a) Área foliar, b) pares de folhas, c) altura do caule e d) razão raiz/parte aérea de plantas de Tabebuia avellanedae Lorentz ex Griseb., cultivadas por três meses em diferentes intensidades de luz e colonizadas por fungos micorrízicos selecionados $(\boldsymbol{\Delta})$ ou nativos $(\triangle)$. Valores com a mesma letra, para o efeito de luz, não diferem significativamente entre si, pelo teste de Tukey $(\mathrm{p} \leq 0,05)$.

Figure $2-a)$ Leaf area, b) Leaf pairs, c) stem height and d) root/shoot ratio of Tabebuia avellanedae Lorentz Griseb. cultivated for three months in different light intensities and colonized by selected $(\boldsymbol{\Delta})$ or native $(\triangle)$ mycorrhizal fungi. Letters compare light treatments. Means followed by the same letter are not significantly different by the Tukey test $(p \leq 0.05)$.

A intensidade de luz influenciou significativamente a densidade estomática ( $\mathrm{p} \leq 0,01)$ em folhas, a qual dobrou quando a irradiância foi aumentada de $4 \%$ para $70 \%$ de luz, apresentando as folhas a $4 \%$ e $70 \%$ de luz 68 e 140 estômatos $/ \mathrm{mm}^{2}$, respectivamente (Figura 4). A visualização microscópica da epiderme mostrou folhas hipoestomáticas, com estômatos do tipo anomocítico, confirmando os registros realizados por Cabral et al. (2004), para a espécie do mesmo gênero, Tabebuia aurea (Manso) Benth. \& Hook f. ex S. Moore. A densidade estomática foi maior em intensidade de luz mais alta, o que contribui para diminuição da transpiração (POORTER, 1999). Aumento na densidade estomática também pode resultar em incremento na absorção de gás carbônico, o que leva a um melhor aproveitamento dos produtos de fotossíntese gerados durante as reações luminosas da fotossíntese (ABRANS et al., 1992).

Plantas de ambiente ensolarado costumam apresentar estiolamento do caule quando submetidas à baixa intensidade luminosa, comportamento interpretado como estratégia de plantas para evitar o sombreamento por vegetação circundante (BALLARÉ et al., 1997). Esse comportamento foi verificado nas plântulas a 30\% de luz, mas não a 4\%. Smith e Hayward (1985) mostraram que em certas dicotiledôneas não ocorre estiolamento do caule em baixa luminosidade se esta for inferior a $60 \mu \mathrm{mol} \mathrm{m} \mathrm{m}^{-2} \mathrm{~s}^{-1}$. Em plântulas de T. avellanedae a $4 \%$ de luz, a luminosidade máxima foi de $34 \mu \mathrm{mol} \mathrm{m} \mathrm{m}^{-2} \mathrm{~s}^{-1}$, a qual poderia ter sido limitante a ponto de prejudicar o mecanismo de estiolamento.

R. Árvore, Viçosa-MG, v.31, n.3, p.555-566, 2007 
a

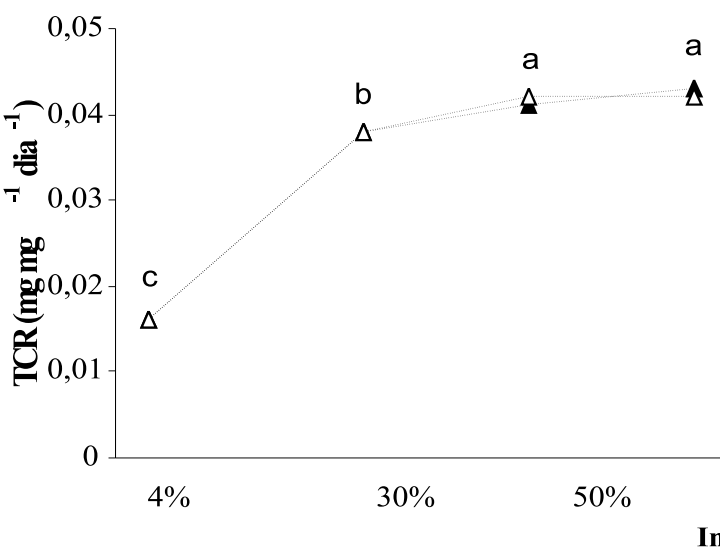

b

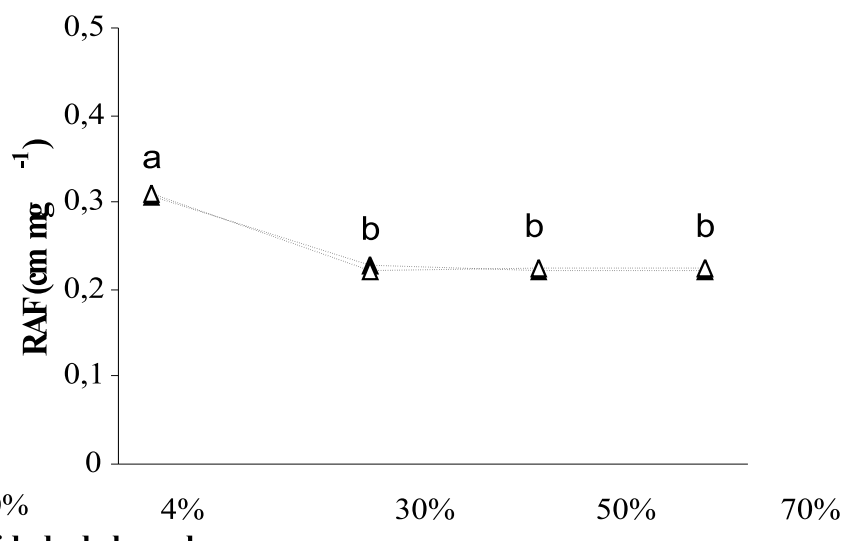

Figura 3 - a) Taxa de crescimento relativo (TCR) e b) razão de área foliar (RAF) de plantas de Tabebuia avellanedae Lorentz ex Griseb., cultivadas por três meses em diferentes intensidades de luz e colonizadas por fungos micorrízicos selecionados $(\boldsymbol{\Delta})$ ou nativos $(\triangle)$. Valores com a mesma letra, para o efeito de luz, não diferem significativamente entre si, pelo teste de Tukey $(\mathrm{p} \leq 0,05)$.

Figure 3 - a) Relative growth rate $(R G R)$ and $b)$ Leaf area rate (LAR) of Tabebuia avellanedae Lorentz Griseb. cultivated for three months under different light intensities and colonized by selected $(\boldsymbol{\Delta})$ or native $(\triangle)$ mycorrhizal fungi. Means followed by the same letter are not significantly different by the Tukey test $(p \leq 0.05)$ for the effect light.

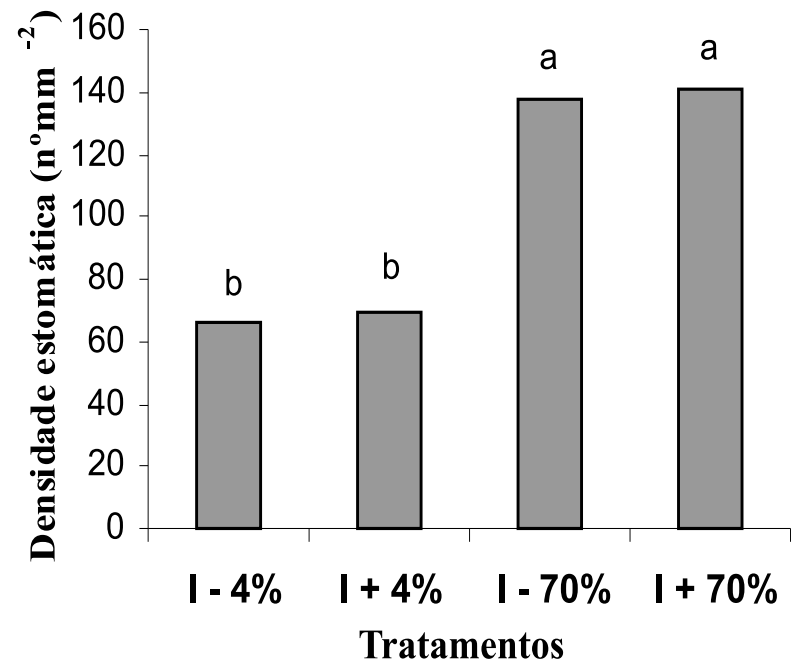

Figura 4 - Densidade estomática de plantas de Tabebuia avellanedae Lorentz ex Griseb, cultivadas por três meses a 4 e $70 \%$ da luz solar e colonizadas por fungos micorrízicos selecionados (I+) ou nativos (I-). Barras com a mesma letra não diferem significativamente entre si, pelo teste de Tukey $(\mathrm{p} \leq 0,05)$.

Figure 4 - Stomatal density of Tabebuia avellanedae Lorentz. Griseb. cultivated for three months at $4 \%$ and $70 \%$ light intensities and colonized by selected $(I+)$ or native (I-) mycorrhizal fungi. Bars followed by the same letter are not significantly different by the Tukey test $(p \leq 0.05)$.

\subsection{Influência da disponibilidade de água e colonização por FMA no crescimento de plantas}

Em plantas sob estresse hídrico, a massa seca total e de folhas foi menor que em plantas não-estressadas. Porém, tanto nas colonizadas por FMA selecionados quanto por nativos, a massa seca de raízes não sofreu influência dos tratamentos aplicados (Quadro 1). Em plantas não estressadas, o número de pares de folhas foi afetado pela inoculação por fungos selecionados, sendo menor que nas plantas não-inoculadas. A altura do caule foi menor em plantas sob estresse hídrico. A área foliar e a razão $\mathrm{R}: P A$ foram afetadas pela deficiência hídrica ( $\mathrm{p}$ $\leq 0,01$ ), sendo a área foliar menor e a R:PA, maior em plantas estressadas (Quadro 1).

A taxa de crescimento relativo (Figura 5a) foi afetada pela deficiência hídrica, nas plantas colonizadas por fungos nativos, sendo maior nas plantas não-estressadas. Observando a Figura 5a, nota-se, ainda, que sob condições normais de hidratação as plantas micorrizadas por fungos selecionados tiveram a TCR ligeiramente deprimida em relação à TCR das plantas micorrizadas por fungos nativos. Em plantas estressadas, notou-se o inverso, ou seja, as plantas micorrizadas por fungos nativos é que apresentaram TCR ligeiramente deprimida em relação às plantas micorrizadas com fungos selecionados. A razão de área foliar não foi afetada pela deficiência hídrica ou pela colonização por FMA selecionados (Figura 5b). 
Quadro1 - Massa seca de área foliar, número de folhas, altura do caule e razão raiz/parte aérea de plantas de Tabebuia avellanedae Lorentz ex Griseb. a 44\% de luz solar submetidas (E+) ou não (E-) por três meses a estresse hídrico e colonizadas por fungos micorrízicos selecionados (I+) ou nativos (I-)

Table 1 - Dry mass, leaf area, number of leaf pairs, stem height and root/shoot ratio of Tabebuia avellanedae Lorentz Griseb. under $44 \%$ of sun light intensity and subjected $(E+)$ or not $(E-)$ to water stress for three months and colonized by selected $(I+)$ or native $(I-)$ mycorrhizal fungi

\begin{tabular}{lccc}
\hline \multicolumn{1}{c}{ Variáveis } & \multicolumn{2}{c}{ Tratamentos } \\
\cline { 2 - 4 } & E-I- & E+I- & E+I+ \\
\hline Massa seca total & $2367 \mathrm{a}$ & $1895 \mathrm{a}$ & $2162 \mathrm{a}$ \\
Massa seca de raiz & $1022 \mathrm{a}$ & $910 \mathrm{a}$ & $1029 \mathrm{a}$ \\
Massa seca de caule & $318 \mathrm{a}$ & $241 \mathrm{~b}$ & $294 \mathrm{ab}$ \\
Massa seca de folhas & & & $1047 \mathrm{a}$ \\
Número de pares de folhas & $5,6 \mathrm{a}$ & $4,3 \mathrm{~b}$ & $4,7 \mathrm{~b}$ \\
Altura do caule & $4,7 \mathrm{~b}$ & $9,3 \mathrm{~b}$ & $10,0 \mathrm{~b}$ \\
Área foliar & $247 \mathrm{a}$ & $153 \mathrm{~b}$ & $170 \mathrm{~b}$ \\
Razão raiz/parte aérea & $0,74 \mathrm{~b}$ & $0,96 \mathrm{a}$ & $0,6 \mathrm{ab}$ \\
\hline
\end{tabular}

Diferenças significativas (Tukey p $\leq 0,05$ ) entre tratamentos são indicadas por letras diferentes.
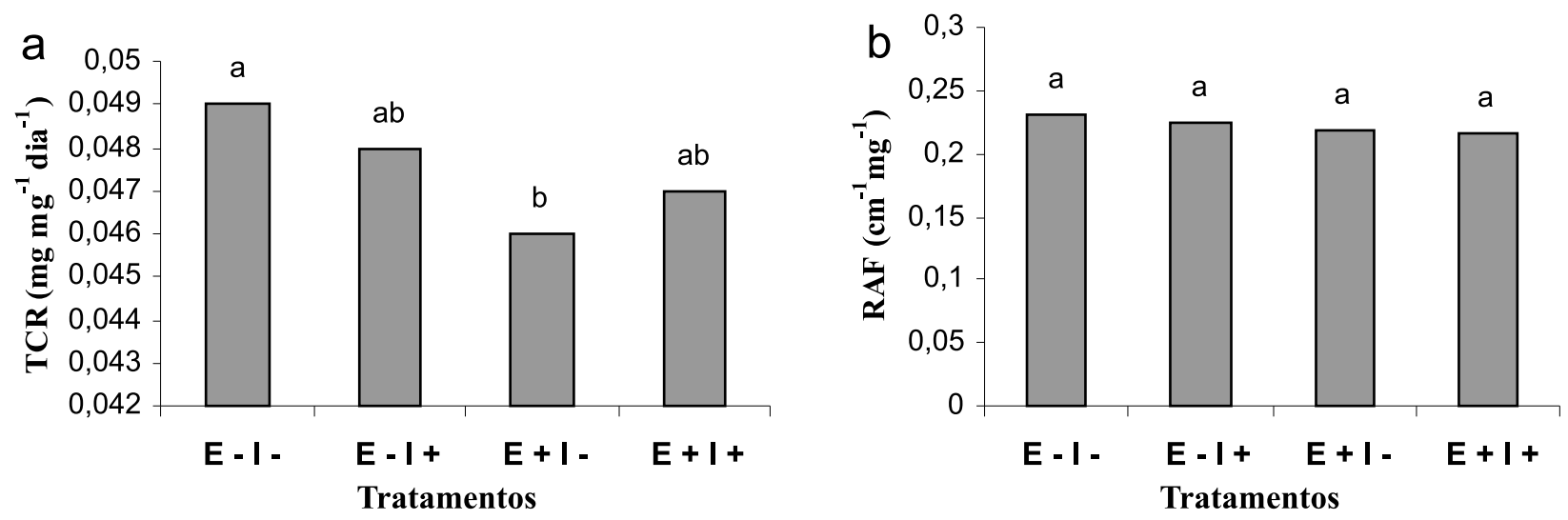

Figura 5 - a) Taxa de crescimento relativo (TCR) e b) razão área foliar (RAF) de plantas de Tabebuia avellanedae Lorentz ex Griseb. a 44\% de luz solar submetidas (E+) ou não (E-) por três meses a estresse hídrico e colonizadas por fungos micorrízicos selecionados (I+) ou nativos (I-). Barras com a mesma letra não diferem pelo teste de Tukey $(\mathrm{p} \leq 0,05)$.

Figure $5-a)$ Relative growth rate $(R G R)$ and $b)$ Leaf area rate (LAR) of plants of Tabebuia avellanedae Lorentz Griseb. grown under $44 \%$ light and submitted $(E+)$ or not $(E-)$ during three months to water stress and colonized by selected (I+) or native (I-) mycorrhizal fungi. Bars with the same letter do not differ for the Tukey test $(p \leq 0.05)$.

Em T. avellanedae, plantas colonizadas por fungos nativos apresentaram respostas de adaptação à seca, como a diminuição da área foliar, através da redução do número de folhas e da expansão de cada uma, mecanismo importante de adaptação a períodos de déficit hídrico, pois diminui a área de transpiração (LECOEUR e SINCLAIR, 1996). As plantas submetidas a estresse hídrico colonizadas por fungos nativos apresentaram maior valor de R:PA que aquelas sem estresse, resultado também encontrado em Tabebuia aurea (CABRAL et al., 2004). Esse comportamento favorece a obtenção de água e está associado à capacidade de resistência à seca (POORTER, 1999). Em plantas colonizadas por fungos nativos, a deficiência hídrica deprimiu a taxa de crescimento relativo (TCR), provavelmente pela inibição da taxa de assimilação líquida (TAL), já que a razão de área foliar (RAF) não variou entre plantas sob estresse das testemunhas.

Menor taxa de crescimento em plantas em deficiência hídrica geralmente é o resultado da diminuição da condutância estomática, pois, ao mesmo tempo que 
a redução da condutância estomática reduz a transpiração, reduz também a entrada de gás carbônico, diminuindo a taxa fotossintética e, conseqüentemente, a taxa de crescimento (LEVITT, 1980).

T. avellanedae em baixa disponibilidade hídrica, independentemente do tipo de fungo associado, mostrou aumento significativo na quantidade do aminoácido prolina em relação às plantas não-estressadas (Figura 6a). Entretanto, as plantas estressadas associadas a fungos selecionados tiveram aumento de mais de três vezes na quantidade de prolina que aquelas estressadas associadas a fungos nativos. As plantas estressadas e colonizadas por FMA nativos, apresentaram maior densidade estomática do que as estressadas colonizadas por fungos selecionados e as não estressadas (Figura 6b). Houve interação significativa entre os fatores deficiência hídrica e FMA, com relação às variáveis prolina e densidade estomática $(\mathrm{p} \leq 0,01)$.

O aumento da densidade estomática encontrada em $T$. avellanedae sob estresse hídrico é uma resposta apresentada por várias espécies submetidas a uma menor disponibilidade hídrica (SILVA et al., 1999), resposta essa que favorece a redução da transpiração em razão da formação de arcos de transpiração mais próximos entre si, o que retém maior umidade na área estomática (LARCHER, 2000).

Em plantas colonizadas por fungos selecionados, observou-se que a deficiência de água no solo não foi tão prejudicial à parte aérea como o foi para as plantas colonizadas por fungos nativos, o que mostra o benefício da inoculação por fungos selecionados para resistência à seca. Sob condições normais de hidratação, as plantas micorrizadas por fungos selecionados apresentaram a TCR ligeiramente reduzida em relação à das plantas micorrizadas por fungos nativos. Já em plantas estressadas notou-se o inverso. Em condições de deficiência hídrica, o aumento da TCR em plantas associadas a fungos selecionados pode indicar que esses fungos não representam custo para as plantas que passam a ser beneficiadas pela associação micorrízica.

A menor densidade estomática em plantas sob estresse hídrico colonizadas por FMA selecionados em relação às plantas em estresse hídrico colonizadas por FMA nativos indica que as primeiras estavam com maior disponibilidade de água que aquelas colonizadas por FMA nativos. Esse resultado parece ser conseqüência do aumento significativo na quantidade do aminoácido prolina em plantas colonizadas por FMA selecionados em relação às colonizadas por FMA nativos. Maior concentração de prolina leva a diminuição do potencial osmótico da folha (AUGÉ, 2001; DIALLO et al., 2001), o que contribui para a redução da transpiração e a manutenção da turgescência, resultando em elevação do potencial de água da planta (LEVITT, 1980). Freqüentemente, a diminuição do potencial de água na planta leva à diminuição da condutância estomática, o que restringe a entrada de gás carbônico e provoca, conseqüentemente, a diminuição da fotossíntese (POORTER, 1999). Em plantas colonizadas por FMA selecionados, o incremento na concentração de prolina pode ter evitado a diminuição na condutância estomática, o que resultou no aumento de biomassa da parte aérea nessas plantas em relação àquelas colonizadas por FMA nativos.

Esses resultados apontaram a maior eficiência da associação com FMA selecionados que com FMA nativos em aumentar a resistência das plantas à seca. Chu et al. (2004) comentaram que a presença da microbiota nativa, incluindo os fungos micorrízicos, pode influenciar o funcionamento de espécies de FMA selecionadas, sendo, portanto, necessário conhecer os efeitos da inoculação no solo natural, sem desinfecção, para prever o grau de sucesso da prática de inoculação em condições de campo. Os resultados indicaram que $T$. avellanedae pode ter sua resistência ao estresse hídrico aumentada em condições de campo com a inoculação por G. clarum e G. etunicatum.

\subsection{Influência da intensidade de luz na colonização micorrízica}

A intensidade de luz afetou significativamente a colonização micorrízica ( $\mathrm{p} \leq 0,01)$, tanto em plantas inoculadas com fungos micorrízicos arbusculares (FMA) selecionados, Glomus clarum e G. etunicatum, quanto naquelas colonizadas por FMA nativos (Figura 7a). Entretanto, na mesma intensidade de luz não houve diferença significativa na porcentagem de colonização entre FMA selecionados (39\%) e nativos (30\%).

Em baixa intensidade de luz (RFA máxima de 34 $\mu \mathrm{mol} \mathrm{m} \mathrm{m}^{-2} \mathrm{~s}^{-1}$, simulando aquela existente em sub-bosque sob denso dossel, a colonização micorrízica foi praticamente nula. Já em alta intensidade de luz (RFA máxima de $600 \mathrm{mmol} \mathrm{m}^{-2} \mathrm{~s}^{-1}$ ), simulando a intensidade existente em clareira de médio porte, os níveis de colonização micorrízica foram significativamente altos. Na variável teor de arbúsculos (Figura 7b) houve interação significativa entre os fatores luz e FMA. 


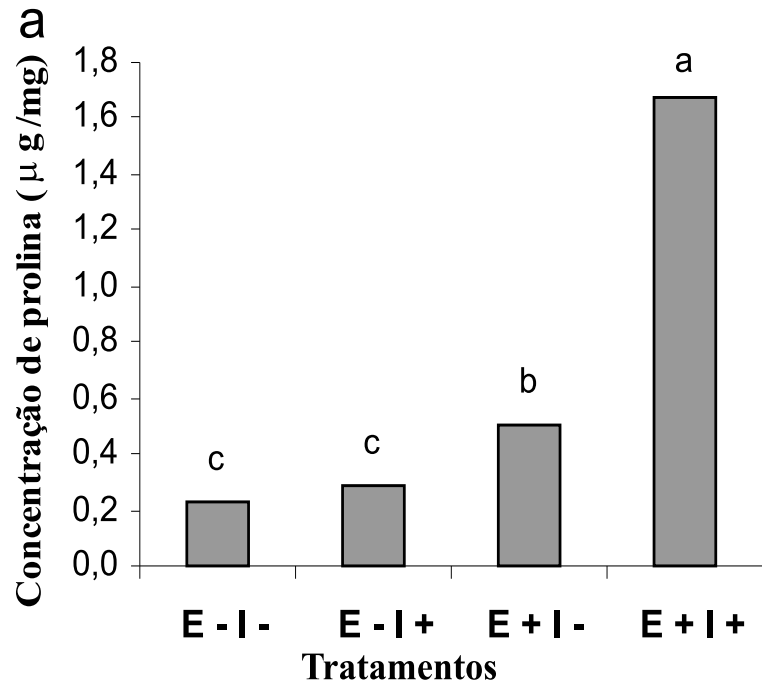

b

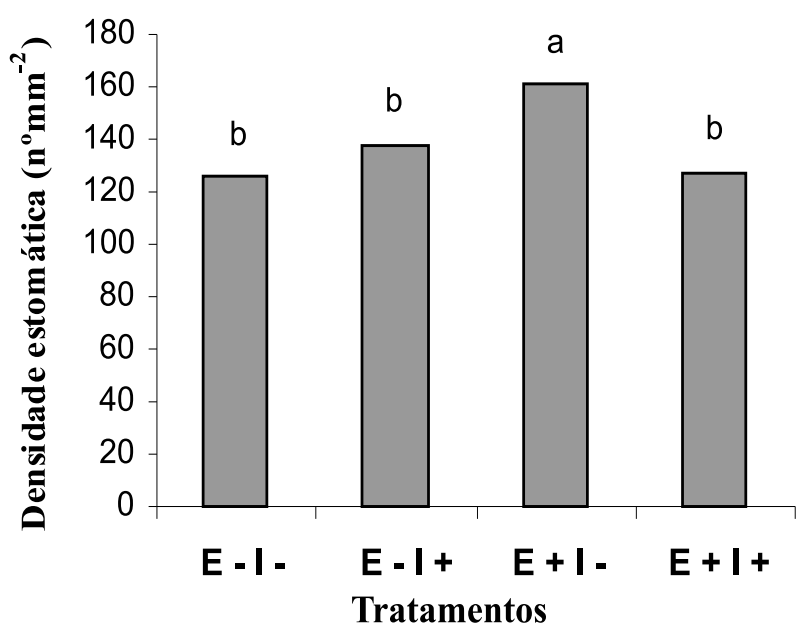

Figura 6 - a) Concentração de prolina e b) densidade estomática de plantas de Tabebuia avellanedae Lorentz ex Griseb. a $44 \%$ de luz submetidas ( $\mathrm{E}+$ ) ou não (E-) por três meses a estresse hídrico e colonizadas por fungos micorrízicos selecionados (I+) ou nativos (I-). Barras com a mesma letra não diferem pelo teste de Tukey $(\mathrm{p} \leq 0,05)$.

Figure 6 - a) Proline levels and b) stomatal density of Tabebuia avellanedae Lorentz Griseb. grown under $44 \%$ light and subjected (E+) or not (E-) to water stress for three months a and colonized by selected (I+) or native (I-) mycorrhizal fungi. Bars followed by the same letter are not significantly different by the Tukey test $(p \leq 0.05)$.

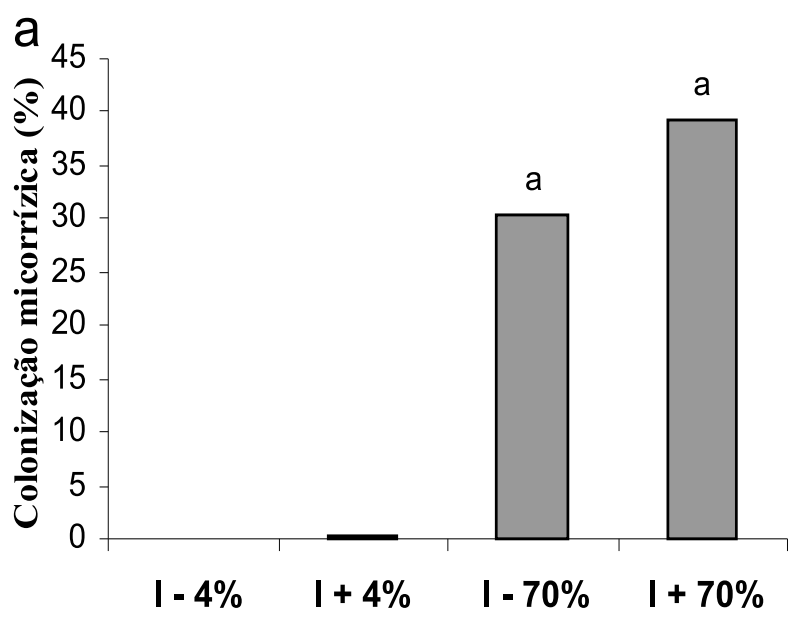

Tratamentos b

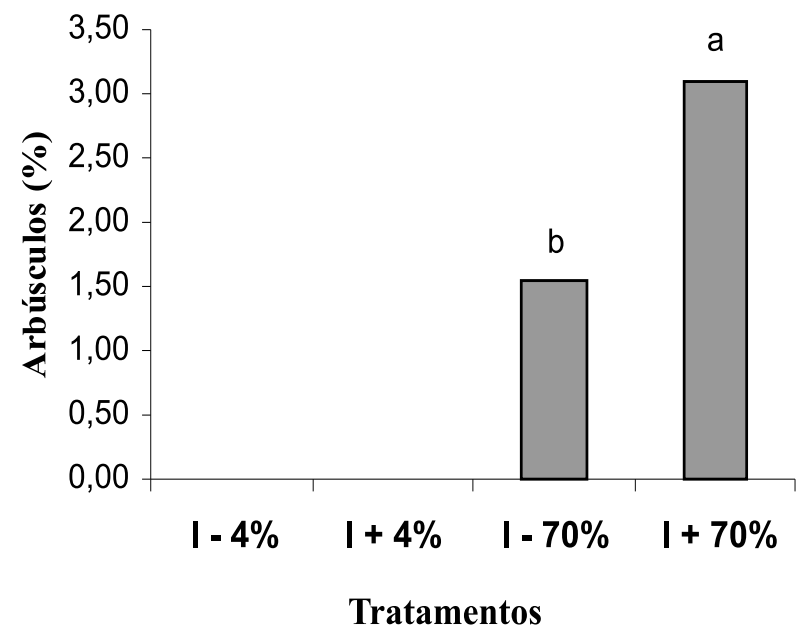

Figura 7 - a) Intensidade de colonização e b) porcentagem de arbúsculos em raízes de plantas de Tabebuia avellanedae Lorentz ex Griseb. crescendo por três meses e $44 \%$ de luz a 4 e $70 \%$ da luz solar total e colonizadas por fungos micorrízicos selecionados ( + +) ou nativos (I-). Barras com a mesma letra não diferem pelo teste de Tukey $(\mathrm{p} \leq 0,05)$.

Figure $7-a)$ Intensity of colonization and b) percentage of arbuscules in roots of Tabebuia avellanedae Lorentz Griseb. grown for 3 months under $4 \%$ and $70 \%$ of the total solar light and colonized by selected (I+) or native (I-) mycorrhizal fungi. Bars followed by the same letter are not significantly different by the Tukey test $(p \leq 0.05)$. 
A intensidade de luz afetou a colonização micorrízica, sendo a colonização mais alta em maior nível de luz, tanto em plantas inoculadas por FMA selecionados, Glomus clarum e G. etunicatum, quanto naquelas colonizadas por FMA nativos. Em baixa intensidade de luz (RFA máxima de $34 \mu \mathrm{mol} \mathrm{m} \mathrm{m}^{-2} \mathrm{~s}^{-1}$ ), simulando aquela em sub-bosque sob denso dossel da floresta, a colonização micorrízica foi praticamente nula. A inibição da colonização micorrízica pela baixa intensidade luminosa tem sido observada em espécies herbáceas (MARSCHNER e TIMONEN, 2005) e arbóreas florestais (AARLE et al., 2005). A baixa colonização micorrízica em baixa intensidade de luz, encontrada em $T$. avellanedae e em outras espécies, é explicada pela menor alocação de carbono para as raízes (MARSCHNER e TIMONEN, 2005) e menor exsudação radicular (GEHRING, 2003), uma vez que os FMA necessitam dos produtos de fotossíntese da planta hospedeira (HURST et al., 2002). A ineficiência na obtenção do fósforo (SMITH e GIANINAZZI-PEARSON, 1988) e a competição entre os simbiontes por carbono (HURST et al., 2002; BÉREAU et al., 2005) também são mecanismos propostos para explicar a redução na colonização micorrízica em baixa intensidade luminosa.

Em alta intensidade de luz (RFA máxima de 600 $\mu \mathrm{mol} \mathrm{m} \mathrm{m}^{-2} \mathrm{~s}^{-1}$ ) e simulando aquela existente em clareira de médio porte, os níveis de colonização micorrízica foram significativamente mais altos. Em alta intensidade de luz foi encontrada uma quantidade de arbúsculos significativamente maior em plantas colonizadas por FMA selecionados que naquelas colonizadas por FMA nativos. Isso indica que a inoculação pode ter levado a uma maior eficiência na troca de material entre fungo e planta, já que os arbúsculos funcionam como interface nas trocas nutricionais entre os simbiontes (SMITH e GIANINAZZI-PEARSON, 1988).

O tipo de fungo, nativos ou selecionados, associado às plantas não afetou a intensidade de colonização micorrízica. Entretanto, Soares et al. (2003) encontraram maior colonização em T. avellanedae por Glomus etunicatum, G. clarum e G. sp. que em uma população nativa de FMA de um remanescente de Mata Atlântica. Essa discrepância entre os resultados pode ser explicada pelo fato de a população de FMA nativa ser diferente nos dois casos, já que a distribuição de populações de FMA não é uniforme e muito variável na natureza (SIQUEIRA, 1994), ou porque a comunidade de FMA nativa utilizada neste trabalho foi similar à do inóculo, composta por Glomus clarum e G. etunicatum, já que o gênero Glomus é comum em solos sob vegetação de Mata Atlântica (MAZZONI-VIVEIROS e TRUFEM, 2004).

A intensidade de colonização por FMA encontrada em T. avellanedae, em quaisquer das condições experimentadas, foi abaixo de $50 \%$, valor de intensidade considerado médio a baixo (ZANGARO et al., 2003). Carneiro et al. (1998) e Soares et al. (2003) também encontraram, em T. impetiginosa (Mart.) Standl. e T. heptaphyla Vell. Tol., colonização de intensidade similar à deste trabalho. T. avellanedae é espécie de final de sucessão (SOARES et al., 2003; ZANGARO et al., 2003), e baixa resposta à colonização micorrízica em mudas de espécies arbóreas nativas foi associada a espécies de final de sucessão (CARNEIRO et al., 1998; ZANGARO et al., 2003). Entretanto, a correlação entre menor colonização e espécies tardias não foi corroborada por estudos de Janos (1980) e Huante et al. (1993), que encontraram maior colonização micorrízica em espécies de final de sucessão.

\section{CONCLUSÃO}

Os resultados permitiram concluir que:

Tabebuia avellanedae apresenta plasticidade à variação de água e luz, o que favorece a sobrevivência ou, mesmo, o estabelecimento da espécie em ambientes subótimos para o máximo crescimento das plântulas e considerável colonização micorrízica por fungos selecionados e nativos. Isso indica que a espécie é passível de inoculação em ambientes naturais, sem que haja supressão da colonização por FMA selecionados pelos fungos nativos.

A ausência de micorrizas em T. avellanedae em intensidade de luz similar a de sub-bosque indica que a limitação da fotossíntese nesse nível de luz torna o custo da simbiose muito alto, suplantando os benefícios que poderiam advir de uma associação com FMA.

A micorrização por fungos selecionados mostrouse benéfica para minimizar os efeitos da deficiência hídrica, indicando a importância da inclusão de uma população de FMA mais eficientes em ambientes suscetíveis à seca. 


\section{REFERÊNCIAS}

AARLE, I. M. et al. Metabolic activity of Glomus intraradices in Arum- and Paris-type arbuscular mycorrhizal colonization. New Phytologist, v.166, p.611-618, 2005.

ABRANS, M. C.; KLOEPPEL, B. D.; KUBISKE, M. E. Ecophysiological and morphological responses to shade and drought in two contrasting ecotypes of Prunus serotina. Tree Physiology, v.10, p.343-355, 1992.

AUGÉ, R. M. Water relations, drought and vesicular-arbuscular mycorrhizal symbiosis. Mycorrhiza, v.11, p.3-42, 2001.

BALLARÉ, C. L.; SCOPEL, A. L.; SÁNCHEZ, R. A. Foraging for light: photosensory ecology and agricultural implications. Plant Environment, v.20, p.820-825, 1997.

BANZATTO, D. A. ; KRONKA, S. N. Experimentação agrícola. 3.ed. Jaboticabal: FUNEP, 1995. 142p.

BÉREAU, M. et al. Do mycorrhizas improve tropical tree seedling performance under water stress and low light conditions? A case study with Dicorynia guianensis (Caesalpiniaceae). Journal of Tropical Ecology, v.21, p.375-381, 2005.

BOKHARI, U. G.; TRENT, J. D. Proline concentrations in water stressed grasses. Journal of Range Management, v.38, n.1, p.37-38, 1985.

CABRAL, E. L.; BARBOSA, D. C. A.; SIMABUKURO, E. A. Crescimento de plantas jovens de Tabebuia aurea (Manso) Benth \& Hook.f. ex S. Moore submetidas a estresse hídrico. Acta Botânica Brasilica, v.18, n.2, p.241-251, 2004.

CARNEIRO, M. A. C. et al. Micorriza arbuscular em espécies arbóreas e arbustivas nativas de ocorrência no Sudoeste do Brasil. Cerne, v.4, n.1, p.129-145, 1998.

CARVALHO, C. J. R. Respostas de plantas de Schizolobium amazonicum (S. parahyba var. amazonicum) e Schizolobium parahyba (Schizolobium parahybum) à deficiência hídrica. Revista Árvore, v.29, n.6, p.907-914, 2005.
CHU, E. Y.; YARED, J. A. G.; MAKI, H. J. I. O. Efeitos da inoculação micorrízica e da adubação fosfatada em mudas de Vochysia maxima Ducke. Revista Árvore, v.28, p.157-165, 2004.

DIALLO, A. T.; SAMB, P. I.; ROY-MACAULEY, H. Water status and stomatal behaviour of cowpea, Vigna unguiculata (L.) Walp, plants inoculated with two Glomus species at low soil moisture levels. European Journal of Soil Biology, v.37, p.187-196, 2001.

ENTRY, J. A. et al Influence of adverse soil conditions on the formation and function of arbuscular mycorrhizas. Advances in Environmental Research, v.7, p.123-138, 2002.

EVANS, J. R.; EDWARDS, E. Nutrient uptake and use in plant growth. In: NET ECOSYSTEM EXCHANGE CRC WORKSHOP, 2001, Canberra. Proceedings. Canberra: Cooperative Research Centre for Greenhouse Accounting, 2001. p.75-81.

GEHRING, C.A. Growth responses to arbuscular mycorrhizae by rain forest seedlings vary with light intensity and tree species. Plant Ecology, v.167, p.127-139, 2003.

GIANINAZZI, S.; GIANINAZZI-PEARSON, V. Cytology, histochemistry and immunocytochemistry as tools for studying structure and function in endomycorrhiza. In: Methods in Microbiology, v.24, p.109-139, 1992.

HUANTE, P.; RINCON, E.; ALLEN, E. B. Effect of vesicular-arbuscular mycorrhizae on seedlings growth of four tree species from the tropical deciduous forest in Mexico. Mycorrhiza, v.2, p.141-145, 1993.

HUNT, R. Plant growth curves. The functional approach to plant growth analysis. London: Edward Arnold, 1982. 248p.

HURST, S. E.; TURNBULL, M. H.; NORTON, D. A. The effect of plant light environment on mycorrhizal colonisation in field-grown seedlings of podocarp-angiosperm forest tree species. New Zealand Journal of Botany, v.40, p.65-72, 2002.

R. Árvore, Viçosa-MG, v.31, n.3, p.555-566, 2007 
JANOS, D. P. Vesicular-arbuscular mycorrhizae affect lowland tropical rain forest plant growth. Ecology, v.61, p.151-162, 1980.

LARCHER, W. Ecofisiologia vegetal. São Carlos: Rima, 2000. 531p.

LECOEUR, J.; SINCLAIR, R. T. Field pea transpiration and leaf growth in respose to soil water deficits. Crop Science, v.36, p.331-335, 1996.

LEE, D. W. et al. Effects of irradiance and spectral quality on the seedlings of jelutong (Dyera costulata). Journal of Tropical Forest Science, v.11, p.132-147, 1999.

LEVITT, J. D. Responses of plants to environmental stresses. 2.ed. London: Academic Press, 1980. v.1.497p.

MARSCHNER, P.; TIMONEN, S. Interactions between plant species and mycorrhizal colonization on the bacterial community composition in the rhizosphere. Applied Soil Ecology, v.28, p.23-36, 2005.

MAZZONI-VIVEIROS, S.; TRUFEM, S. F. B. Efeitos da poluição aérea edáfica no sistema radicular de Tibouchina pulchra Cogn. (Melastomataceae) em área de Mata Atlântica: associações micorrízicas e morfologia.

Revista Brasileira de Botânica, v.27, p.337-348, 2004.

POORTER, L. Growth responses of 15 rainforest tree species to a light gradient: the relative importance of morphological and physiological traits. Functional Ecology, v.13, p.396-410, 1999.
SILVA, H. et al. Efecto del déficit hídrico en la anatomía foliar de seis cultivares de poroto Phaseolus vulgaris. Revista Chilena de Historia Natural, v.72, p.219-235,1999.

SIQUEIRA, J. O. Micorrizas Arbusculares. In: ARAUJO, R.S; HUNGRIA, M. (Eds).

Microrganismos de importância agrícola. Brasília: Embrapa-SPI, 1994. p.151-194.

SMITH, H.; HAYWARD, P. Fluence rate compensation of the perception of red: far-red ratio by phytochrome in light-grown seedlings. Photochemistry and Photobiology, v.42, p.685-688, 1985.

SMITH, S. E.; GIANINAZZI-PEARSON, V.

Physiological interactions between symbionts in vesicular-arbuscular mycorrhizal plants. Annual Review Plant Physiology Plant Molecular Biology, v.39, p.221-244, 1988.

SOARES, A. C. F. et al. Produção de mudas de ipê-roxo inoculadas com fungos micorrízicos arbusculares.

Magistra, v. 15, n. 2, p. 123-127, 2003.

STATISOFT, Inc. Statistica (data analysis software system), version 6. 2001. (www.statsoft.com.).

TROUVELOT, A.; KOUGH, J. L.; GIANINAZZIPEARSON, V. Mesure du taux de mycorhization VA d'un système radiculaire. Recherche de méthodes d'estimation ayant une signification fonctionnelle. In: GIANINAZZI-PEARSON, V.; GIANINAZZI, S.(Eds.) Mycorrhizae: physiology and genetics. Paris: INRA, 1986. p.217-221.

ZANGARO, W. et al. Mycorrhizal response and successional status in 80 woody species from south Brazil. Journal of Tropical Ecology, v.19, p.315-324, 2003. 